\title{
Auf gutem Weg: Direkte Demokratie in Berlin.
}

\section{Christian Pestalozza}

Um es vorweg zu sagen: Die Berliner leben in einem Land, das der direkten Demokratie auch jenseits der - hier nicht interessierenden - Wahlen freundlich gesinnt ist. 1995 haben die politisch Verantwortlichen begonnen, sich auf das 1974 getilgte direktdemokratische Vermächtnis der Verfassung von $1950 \mathrm{zu}$ besinnen. 2005 und 2006 sind sie auf diesem Weg fortgeschritten. Weiteres ist möglich, manches nötig. Die Berliner machen von dem Angebot lebhaften Gebrauch. Ihre Initiativ- und Abstimmungsfreudigkeit geht mit einer deutlichen Wahlmüdigkeit einher; über die Zusammenhänge, Auswirkungen und Reaktionen wird andernorts nachzudenken sein.

\section{A. Das Grundgesetz - verhalten großzügig}

Das Grundgesetz setzt - wie das sonstige Bundesrecht - dem Land keine Grenzen. Art. 20 Abs. 2 Satz 2 GG, der unmittelbar auch für die Länder gilt, fordert „Abstimmungen" im Lande - außerhalb der Art. 29, 118 a GG - wohl nicht, aber rechnet mit ihnen und toleriert sie. Art. 28 Abs. 1 Satz 4 GG ist ein ermutigender Wink am Rande, nicht mehr, nicht weniger. Aus Art. 28 Abs. 1 Satz 1 GG folgt nichts; daß der Bund auf seiner Ebene Abstimmungen kaum kennt, zwingt die Länder nicht zu vergleichbarer Enthaltsamkeit. Art. 28 Abs. 1 Sätze 2 und 3 GG betreffen Wahlen, nicht Abstimmungen und Abwahlen.

B. Die Landesverfassung - zerfahren aufgeschlossen

Die Landesverfassung widmet sich der direkten Demokratie ausführlich und zunehmend zugewandt, wenngleich noch immer unvollständig und hier und da imperfekt.

\section{Erste Andeutungen in den „Grundlagen“}

Erste, recht allgemeine Hinweise enthalten die im Abschnitt I „Die Grundlagen“ stehenden Art. 2 und 3 Abs. 1 Satz 1 VvB. Sie regeln nichts wirklich, sondern kündigen vage an, was später konkreter folgen wird. Sie sind trotz ihrer überwiegend deklaratorischen Natur nicht überflüssig; eine Verfassung soll auch „erzählen“ dürfen. Art. 2 berichtet:

„Träger der öffentlichen Gewalt ist die Gesamtheit der Deutschen, die in Berlin ihren Wohnsitz haben. Sie üben nach dieser Verfassung ihren Willen unmittelbar durch Wahl zu der Volksvertretung und durch Abstimmung, mittelbar durch die Volksvertretung aus. Die Vorschriften dieser Verfassung, die auch 
anderen Einwohnern Berlins eine Beteiligung an der staatlichen Willensbildung einräumen, bleiben unberührt.“

Dem fügt Art. 3 Abs. 1 Satz 1, neben Satz 2 die Gewaltenteilung thematisierend, hinzu:

„Die gesetzgebende Gewalt wird durch Volksabstimmungen, Volksentscheide und durch die Volksvertretung ausgeübt, die vollziehende Gewalt durch die Regierung und die Verwaltung sowie in den Bezirken im Wege von Bürgerentscheiden."

Manches davon könnte schon an dieser Stelle genauer geraten: Die noch nicht sechzehnjährigen Deutschen sind sicher nicht Träger der öffentlichen Gewalt (Art. 2 Satz 1), die sechzehn- und siebzehnjährigen nur sehr begrenzt. Reicht der am Tag oder am Vortag der Willensbekundung begründete Wohnsitz (Art. 2 Satz 1) aus? Die anderen Einwohner (Art. 2 Satz 3) sind gewiß nicht an einer staatlichen Willensbildung, sondern allenfalls an der Bildung des staatlichen Willens beteiligt, ja bei dem den „staatlichen“ Willen ersetzenden Bürgerentscheid nicht einmal das. Überdies spricht die Verfassung selbst später (Art. 61 Abs. 1 Satz 1, 62 Abs. 1 Satz 2) von ,politischer“, nicht von „staatlicher“ Willensbildung. Und zu Art. 3 Abs. 1 Satz 1 könnte man fragen, ob nicht auch Volksentscheide Volksabstimmungen sind, ${ }^{1}$ und warum der Volksvertretung, Regierung und Verwaltung nicht schlicht das Volk und die Bürger (in den Bezirken) zur Seite gestellt sind.

\section{Am Rande der direkten Demokratie}

\section{Altbestand: Abwahl des Abgeordnetenhauses}

Im Kern unverändert hat allein das Recht des Volkes, das Abgeordnetenhaus vorzeitig aufzulösen, von 1950 bis heute überdauert. Die 1950 ebenfalls eingeräumte Volksgesetzgebungskompetenz stand bis 1974 allein auf dem Papier, weil ein Ausführungsgesetz fehlte, wurde dann - spät, aber aufrichtig - gestrichen und erst 1995 wieder eingeführt.

Bereits Art. 39 Abs. 1 Sätze 1 und 3 der Verfassung von 1950 sahen vor, daß das Abgeordnetenhaus auch durch Volksentscheid, an dem sich mindestens die Hälfte der Wahlberechtigten beteiligte, aufgelöst werden konnte. Die Zuständigkeit über-

1 Bis zum Fünften Änderungsgesetz 2005 begnügte sich Art. 3 Abs. 1 Satz 1 mit den Worten „Die gesetzgebende Gewalt wird durch Abstimmung und durch die Volksvertretung ausgeübt." Warum man 2005 die „Volksentscheide“ dazwischen preßte (und bei der Gelegenheit beiläufig den Satz auch noch sprachlich verschlechterte [einmal oder dreimal „durch“" wäre angemessen]), ist unklar. Jedenfalls verdankt sich der unschöne Wortlaut nicht dem ursprünglichen Fraktionsentwurf (AH-Drs. 15/3707), sondern dem federführenden Rechtsausschuß (Ausschußprotokoll $15 / 56)$. 
lebte die Säuberungsaktion von $1974,{ }^{2}$ bei deren Gelegenheit klargestellt wurde, daß dem Volksentscheid ein Volksbegehren voranzugehen habe. ${ }^{3} 1981$ erhielt die Auflösung durch Volksabstimmung einen eigenen Absatz 3 im neu gestalteten Art. 39 VvB und wurde ,,alles Nähere“ in die Hand des einfachen Gesetzgebers gelegt. ${ }^{4}$ Die „Überarbeitung“ der Verfassung $1995^{5}$ zerlegte das Thema. Sie beließ im Abschnitt über das Abgeordnetenhaus den dürren Satz „Die Wahlperiode kann auch durch Volksentscheid vorzeitig beendet werden“ (Art. 54 Abs. 3 VvB) und kam darauf unpassend im Abschnitt „Gesetzgebung“ wieder zurück (Art.62 Abs. 36, 63 Abs. $3^{7}$ VvB). Die Verfassungsänderung $2006^{8}$ behob die irritierende Zerlegung nicht. Absatz 3 des Art. 62 wurde zu Absatz 6 desselben Artikels; die im Verfassungstext neue Unterscheidung zwischen Unterstützung und Zustandekommen des Volksbegehrens schlägt sich auch hier im Art. 63 Abs. 3 VvB, der zudem eine Frist von vier Monaten für das Zustandekommen einführt, ${ }^{9}$ nieder. ${ }^{10}$ Einfachgesetzlich widmen sich (u.a.) dem Thema $\S \S 10$ ff. des Abstimmungsgesetzes. ${ }^{11}$

Die geltende Regelung ist nicht unangemessen. ${ }^{12}$ Fünf andere Länder kennen Entsprechendes..$^{13}$ Eine andere Frage ist es, ob die Einrichtung als solche sinnvoll

2 17. Änderungsgesetz vom 22. November 1974, GVB1. S. 2741.

3 Art. I Nr. 2 des Änderungsgesetzes stellte dem bisherigen Satz 3 des Art. 39 Abs. 1 VvB, der nun Satz 4 wurde, einen neuen Satz 3 voran: „Ein Volksentscheid ist herbeizuführen, wenn ein Fünftel der Wahlberechtigten einem Volksbegehren zugestimmt hat.“

4 Satz 4 i.d.F. des 20. Änderungsgesetzes vom 26. Februar 1981, GVB1. S. 346.

5 Gesetz vom 23. November 1995, GVB1. S. 779.

6 ,Volksbegehren können auch auf die vorzeitige Beendigung der Wahlperiode des Abgeordnetenhauses gerichtet werden."

7 Der Sätze 1-3 des bisherigen Art. 39 VvB übernimmt und dem Satz 3 klarstellend die Wörter „und die Mehrheit für die vorzeitige Beendigung stimmt" anfügt.

8 Achtes Gesetz zur Änderung der Verfassung von Berlin vom 25. Mai 2006, GVB1. S. 446.

9 Die Entwurfsbegründung meint, die Verfahrenserleichterungen des neuen Art. 62 Abs. 4 [Satz 2] kämen auch dem Auflösungsbegehren zugute (AH-Drs. 15/5038, S. 7 zu Art. 63 Abs. 3). Das wäre sinnvoll - aber woraus soll sich das ergeben? Art. 63 Abs. 3 verweist nicht auf Art. 62 Abs. 4 und nennt für den Auflösungsentscheid überhaupt keine Frist, Art. 62 Abs. 4 behandelt ersichtlich (vgl. seine Sätze 3 und 4!) nur Volksentscheide über Gesetze und sonstige Beschlüsse, und Art. 62 Abs. 6 betrifft allein das Auflösungsbegehren, nicht auch den Auflösungsentscheid. - Die Nachlässigkeit der Redaktion des Art. 62 VvB fordert auch hier ihre Opfer. Das Mindeste wäre gewesen, durch einen Satz 2 des Art. 62 Abs. 6 die entsprechende Geltung des Absatzes 4 des Art. 62 anzuordnen. So aber hängen die sicher sinnvollen Bestimmungen des $\S 29$ Abs. 1 Nr. 2 und Abs. 3 AbStG in der Luft.

10 ,Ein Volksbegehren, das die vorzeitige Beendigung der Wahlperiode des Abgeordnetenhauses zum Gegenstand hat, bedarf zum Nachweis der Unterstützung der Unterschriften von mindestens 50000 der zum Abgeordnetenhaus Wahlberechtigten. Es kommt zustande, wenn mindestens ein Fünftel der zum Abgeordnetenhaus Wahlberechtigten innerhalb von vier Monaten dem Volksbegehren zustimmt.“

11 Gesetz über Volksinitiative, Volksbegehren und Volksentscheid (Abstimmungsgesetz - AbStG) vom 11. Juni 1997 (GVBl. S. 304), geändert durch Gesetz vom 20. Februar 2008 (GVB1. S. 22).

12 Auch wenn selten von ihr Gebrauch gemacht werden sollte und sie kaum je erfolgreich sein wird. 1981 bewegte ein Verfahren, das großen Zulauf fand, das Abgeordnetenhaus immerhin 
ist. Es mag heilsam sein, wenn Gewählte nicht nur wissen, daß ihr Mandat ein zwar wiederholbares, aber auch endliches ist, sondern darüber hinaus im Extremfall ein vorzeitiges Ende gewärtigen müssen. Aber, genauer besehen, handelt es sich doch um ein recht ungehobeltes Instrument. Die vorzeitige Auflösung bestraft auch diejenigen, die den Unmut der Bevölkerung gar nicht verursacht und verdient haben mögen, also insbesondere die Opposition. Nicht nur ist die Aussicht, daß sich bei Neuwahlen die Mehrheitsverhältnisse ändern, vage - sie kommt auch denen, die von ihrer Partei nicht wieder aufgestellt werden, gar nicht zugute. Vielleicht aber hat sich die Weisheit der Verfassung 1981 gezeigt, als das Abgeordnetenhaus der realistisch drohenden Schmach der Fremdauflösung durch Selbstauflösung entging.

\section{Neueres: Die Initiative}

Am Rande der direkten Demokratie steht auch die 1995 eingeführte und 2006 modifizierte Initiative i.S. des Art. 61 VvB. 1995 hieß es:

„Art. 61 (1) Alle Einwohner Berlins haben das Recht, das Abgeordnetenhaus im Rahmen seiner Entscheidungszuständigkeiten mit bestimmten Gegenständen der politischen Willensbildung, die Berlin betreffen, zu befassen. Die Initiative muß von 90000 volljährigen Einwohnern Berlins unterzeichnet sein. Ihre Vertreter haben das Recht auf Anhörung in den zuständigen Ausschüssen.

(2) Initiativen zum Landeshaushalt, zu Dienst- und Versorgungsbezügen, Abgaben, Tarifen der öffentlichen Unternehmen sowie Personalentscheidungen sind unzulässig.

(3) Das Nähere regelt ein Gesetz.“

Die 1997 erlassenen Ausführungsregelungen ${ }^{14}$ tauften die von der Verfassung schlicht so genannte „Initiative“ alsbald in „Volksinitiative“ um, nicht beachtend, daß die Zuständigkeit nicht allein dem „Volk“ i.S. des Staatsvolkes, also den wahlberechtigten Deutschen in Berlin, sondern auch allen anderen volljährigen Einwohnern Berlins zukommen sollte, so daß, wenn man einen Zusatz wünscht, der die Autoren der Initiative beschreibt, besser von Einwohnerinitiative die Rede wäre. Die mißratene Terminologie hat sich bis heute gehalten und offenbar auch außerhalb der Normen Anklang gefunden. ${ }^{15}$

zur Selbstauflösung - auch das ein beachtlicher „Erfolg“. Zu jüngeren Abwahlbegehren vgl. die Übersicht auf der Website http://bb.mehr-demokratie.de/3502.html.

13 Baden-Württemberg Art. 43 Abs. 2, Bayern Art. 18 Abs. 3, Brandenburg Art. 76 Abs. 1 Satz 2, 77 Abs. 1 und 3 Satz 2, 78 Abs. 3, Bremen Art. 76 Abs. 1 lit. b und Abs. 2, RheinlandPfalz Art. 109 Abs. 1 Nr. 2, Abs. 2-4.

14 Gesetz über Volksinitiative, Volksbegehren und Volksentscheid vom 11. Juni 1997 (GVB1. S. 304; Kursivdruck nicht im Original); Verordnung zur Durchführung des Gesetzes über Volksinitiative, Volksbegehren und Volksentscheid (Abstimmungsordnung) vom 3. November 1997 (GVBl. S. 583).

15 In anderen Ländern sogar im Verfassungstext. 
Sinn und Nutzen der Neuerung sind unklar. ${ }^{16}$ Art. 17 GG verleiht seit jeher jedem das Recht, sich einzelnen oder in Gemeinschaft mit anderen mit Bitten oder Beschwerden u.a. an die Volksvertretung zu wenden. Seit 1969 sah die Landesverfassung einen Petitionsausschuß vor (Art. 32 Abs. 4 VvB i.d.F. der Änderung von 1969, Art. 46 VvB 1995), und seit 1990 wiederholt Art. 34 VvB ${ }^{17}$ sinngemäß Art. 17 GG. Wozu nun also noch mit verfassungsänderndem Getöse ein äußerst aufwendiges und zugleich beschränktes Massenpetitionsrecht? ${ }^{18}$ Der Aufwand: 90000 volljährige Einwohner Berlins mußten sich finden, um nach Art. 61 tun zu können, was jeder einzelne grundrechtsmündige Mensch ohnehin auch allein oder zusammen mit anderen, gleichgültig wie vielen, tun kann. Die Beschränkung: Nicht jede Bitte oder Beschwerde kann vorgetragen werden, vielmehr nur Gegenstände der politischen Willensbildung, die Berlin betreffen und zudem in die Entscheidungszuständigkeit des Abgeordnetenhauses fallen, und von ihnen nicht einmal alle, denn Art. 61 Abs. 2 VvB schloß Gewichtiges furchtsam aus. Der einzige Zugewinn liegt wohl darin, daß die Initiatoren mit einer Petition i.S.d. Art. $61 \mathrm{VvB}$ im Ausschuß gehört werden müssen und ins Plenum des Abgeordnetenhauses vordringen können, während die gängige Petition über den Ausschuß kaum hinausgelangen dürfte, jedenfalls keinen Anspruch darauf hat. Der andere Vorteil der Hochstilisierung der Massenpetition zur Initiative i.S.d. Art. $61 \mathrm{VvB}$ könnte darin liegen, daß den Petenten Kosten abgenommen werden; aber davon lese ich nirgends.

2006 zeigte der verfassungsändernde Gesetzgeber - begrenzte - Einsicht. Zwar trennte er sich nicht von der überflüssigen Einrichtung (was er ohne Beteiligung des Volkes hätte tun können, Art. 100 Satz 2 VvB), aber erleichterte doch ihre Nutzung. ${ }^{19}$ „Nur“ 20000 Einwohner müssen es seitdem sein, nicht 90000 , und es dürfen nun auch die Sechzehn- und Siebzehnjährigen mitreden. ${ }^{20}$ Zudem sorgte die Streichung des Absatzes 2 des Art. 61 VvB sachgerecht dafür, daß auch Initiativen ,zum

16 Auch wenn sieben Länder Vergleichbares kennen: Brandenburg Art. 76, Mecklenburg-Vorpommern Art. 59, Niedersachsen Art. 47, Nordrhein-Westfalen Art. 67 a, Rheinland-Pfalz Art. 108 a, Sachsen-Anhalt Art. 80, Schleswig-Holstein Art. 41. Vgl. auch Bremen Art. 87 und Thüringen Art. 68: Bürgerantrag sowie Hamburg Art. 29 (Volkspetition). - Die Parlamentaria sind, soweit ich sehe, unergiebig (Entwurf AH-Drs. 12/4874; 1. Lesung AH-PIPr. 12/75, S. 6407-6411; Beschlußempfehlung des Rechtsausschusses AH-Drs. 12/5637; 2. Lesung AHPIPr. 12/86, S. 7400-7408). Der Entwurf lehnte sich an den 2. Bericht (Schlußbericht) der Enquête-Kommission „Verfassungs- und Parlamentsreform“ - 12. Wahlperiode - vom 18. Mai 1994, AH-Drs. 12/4376, an; dort findet sich (vgl. S. 20) keine Erläuterung der hier interessierenden Details.

17 Durch Gesetz vom 3. September 1990 (GVBl. S. 1877) als Art. 21 c eingefügt, 1995 zu Art. 34 umnumeriert.

18 Auch die Begründung zum Gesetz über Volksinitiative, Volksbegehren und Volksentscheid (AH-Drs. 13/709, S. 7 li. Sp.) charakterisiert die Initiative als Massenpetition.

19 Art. I Nr. 7 des Änderungsgesetzes 2006.

20 Eine gewisse Anpassung an die Verfassungsänderungen von 2005, Art. 70 Abs. 1, 72 Abs. 2 VvB betreffend. Die dortige Absenkung des Wahl- und Abstimmungsalters auf Bezirksebene kommt allerdings nicht allen „Einwohnern“ Berlins, sondern nur den Deutschen und den Staatsangehörigen anderer Mitgliedstaaten der Europäischen Union zugute. 
Landeshaushalt, zu Dienst- und Versorgungsbezügen, Abgaben, Tarifen der öffentlichen Unternehmen sowie Personalentscheidungen" zulässig sind. ${ }^{21}$

Unverändert blieb der verfehlte Standort der Regelung. Mit „Gesetzgebung“ hat die Initiative nichts zu tun, und so wie sie ausgestaltet ist, kann $\operatorname{sie}^{22}$ auch nicht in ein Volksbegehren, das auf Gesetzgebung zielt, überführt werden. Der verfassungsändernde Gesetzgeber sollte sich einen redaktionellen Ruck geben: Wenn ihm - wie es scheint - daran liegt, alle Abwahl- und Abstimmungskompetenzen der Bevölkerung in einem Abschnitt zu versammeln, ${ }^{23}$ mag er dies tun. Aber dann müßte er erstens konsequent sein und das Verfassungsreferendum (Art. 100 Satz 2 VvB) in diesen Abschnitt integrieren und die Parlamentsgesetzgebung und Verordnungsetzung exportieren. Zweitens müßte dieser Abschnitt deskriptiv (etwa mit „Einwohner- und Volksabstimmungen") betitelt werden. Drittens müßten einschlägige Passagen außerhalb dieses Abschnitts - z.B. Art. 54 Abs. 3 VvB oder ein bereinigter Abschnitt „Gesetzgebung“ - zur Vermeidung von Wiederholungen und im Interesse der Klarheit auf die betreffenden Volkskompetenzen verweisen. Die Alternative: Die Abwahlkompetenz wird komplett nach Art. 54 Abs. 3 verlagert, die Volksgesetzgebung bleibt im Abschnitt „Gesetzgebung“, in den auch Art. 100 VvB aufgenommen wird. ${ }^{24}$ Aber wohin dann mit der Einwohnerinitiative und der auf ,schlichte" Beschlüsse gerichteten Volksabstimmung? Jene ließe sich mit dem Petitionsrecht, Art. 34 VvB, verschmelzen, diese sich zur Not im Abschnitt „Die Volksvertretung“" unterbringen. ${ }^{25}$

21 Eine besondere Begründung gaben die Fraktionen seinerzeit nicht (vgl. AH-Drs. 15/5038, S. 4, 6). Was hätten sie auch sagen können, ohne ihre Vorgänger bloßzustellen? Zugunsten der Enquête-Kommission „Verfassungs- und Parlamentsreform“ und des sich an ihre Vorschläge anlehnenden Gesetzentwurfs hätte sich allenfalls ins Feld führen lassen, daß nach ihrer Vorstellung auch ein Gesetzentwurf Gegenstand der Initiative sollte sein können (vgl. Art. 46 a Abs. 1 Satz 2 des Entwurfs, AH-Drs. 12/4874, S. 5). Nach der Streichung dieses Passus“ im Gesetzgebungsfahren war kaum noch vorstellbar, wie man die Bereichsausnahmen hätte rechtfertigen können.

22 Anders als z.B. in Brandenburg, Rheinland-Pfalz und Schleswig-Holstein.

23 Wie dies etwa Bremen (Dritter Hauptteil, 2. Abschnitt I Der Volksentscheid, Art. 69-74), Mecklenburg-Vorpommern (3. Abschnitt II Initiativen aus dem Volk, Volksbegehren und Volksentscheid, Art. 59, 60), Niedersachsen (Fünfter Abschnitt Volksinitiative, Volksbegehren und Volksentscheid, Art. 47-50) und Schleswig-Holstein (Abschnitt V Initiativen aus dem Volk, Volksbegehren und Volksentscheid, Art. 41, 42) versuchen.

24 Wie üblich behandelt auch Berlin im Abschnitt „Gesetzgebung“ die Rechtsverordnungen (fragmentarisch) mit (Art. 60 Abs. 3 Satz 1, 64 VvB). Wenn das so bleiben soll, sollte man alles zu dem Thema (einschließlich der bisher nicht geregelten, sondern vorausgesetzten Verkündung) in einem Artikel zusammenfassen (also Art. 60 Abs. 3 VvB insoweit bereinigen) und den Abschnitt mit „Rechtsetzung“ überschreiben.

25 Zur Not deswegen, weil der Abschnitt bislang leider die Funktionen des Abgeordnetenhauses nicht zentral beschreibt, demgemäß auch den schlichten Parlamentsbeschluß nicht thematisiert. Das ließe sich ändern. - Vgl. die Ansätze in Baden-Württemberg Art. 27 Abs. 2, Bremen Art. 101 Abs. 1, Mecklenburg-Vorpommern Art. 20 Abs. 1, Niedersachsen Art. 7, RheinlandPfalz Art. 79 Abs. 1, im Saarland Art. 65 Abs. 2 und 3, in Sachsen Art. 39 Abs. 2, SachsenAnhalt Art. 41 Abs. 1 Sätze 2-4, Schleswig-Holstein Art. 10 Abs. 1 Sätze 2-4, Thüringen Art. 48 Abs. 2; schwächer in Hessen Art. 116 Abs. 2. 


\section{Neuestes: Die Beschlußkompetenzen}

Den traditionellen Kern der Volkskompetenzen macht sicher die Gesetzgebung aus. Seit 2005 läßt Berlin einen Teil seiner Einwohner zusätzlich vollziehende Gewalt (auf Bezirksebene) ausüben, seit 2006 auch nicht gesetzgeberische Entscheidungen anstelle des Parlaments treffen, das Erste wohl wichtiger als das Zweite.

\section{a) Die Landesebene: Volksbeschlüsse}

Die achte Änderung der 1995 überarbeiteten Verfassung im Jahre $2006^{26}$ stellte neben die bereits 1995 wiederbelebte Gesetzgebungszuständigkeit des Volkes die neue Zuständigkeit, auch sonstige Parlamentsbeschlüsse (also nicht nur Gesetzesbeschlüsse) zu ersetzen. Ein neuer Satz 2 des Art. 62 Abs. 1 VvB sieht seitdem vor, daß Volksbegehren auch darauf gerichtet werden können, ,im Rahmen der Entscheidungszuständigkeit des Abgeordnetenhauses zu Gegenständen der politischen Willensbildung, ${ }^{27}$ die Berlin betreffen, sonstige Beschlüsse zu fassen." Das entspricht $^{28}$ den seit 1995 geltenden Voraussetzungen für die Initiative nach Art. 61 Abs. 1 VvB. Für das Verfahren und die Quoren gilt ausweislich der Art. 62, 63 VvB dasselbe wie für die Volksgesetzgebung; von ihnen wird später (sub III.1) noch zu reden sein. Drei Fragen stellen sich:

Erstens: Warum diese Ausdehnung der Volkszuständigkeit? Der verfassungsändernde Gesetzgeber gibt keine Auskunft. ${ }^{29}$ Die Idee, das Volk zu ermächtigen, alle, nicht nur die gesetzgeberischen Entscheidungen des Parlaments zu ersetzen, mag dem Perfektionisten gefallen; aber sie überschätzt wohl das Gewicht der nichtgesetzgeberischen Tätigkeit des Parlaments und ihre Attraktivität für das Volk, unterschätzt vielleicht auch das damit einhergehende Vertrauen, das die Bevölkerung dem „sonstigen“ Tun des Parlaments entgegenbringt. Vielleicht ging es aber auch nur darum, in etwa mit dem Nachbarn Brandenburg (Art. 76 Abs. 1 Satz 1) und mit Schleswig-Holstein (Art. 41 Abs. 1 Satz 1) gleichzuziehen.

Zweitens: Welche nichtgesetzgeberischen Entscheidungen (die ggf. durch das Volk ersetzt werden) fällt eigentlich das Abgeordnetenhaus? Antworten halten das Parlamentsrecht und die Geschäftsordnung des Abgeordnetenhauses bereit. Einige davon hätte der verfassungsändernde Gesetzgeber in seiner Begründung beispielhaft mitteilen können.

Drittens: Was hat es mit den zitierten drei Voraussetzungen auf sich? Es muß sich um Gegenstände der Bildung des politischen Willens handeln, sie müssen Berlin

26 Gesetz vom 25. Mai 2006, GVB1. S. 446.

27 Gemeint ist hier wie überall sicher ,der Bildung des politischen Willens“.

28 Wie auch die Entwurfsbegründung bemerkt (AH-Drs. 15/5038, S. 6 re. Sp.).

29 Vgl. die Entwurfsbegründung, AH-Drs. 15/5038, S. 5 f. Die Sätze „Die Erweiterung der Volksgesetzgebung auf Landesebene knüpft an die Einführung des Bürgerentscheids auf Bezirksebene an. Es wird mehr direkte Demokratie in Ergänzung der parlamentarischen Demokratie ermöglicht" (S. 6 zu Art. 62 und 63) erklären nichts. Der speziell zu Art. 62 Abs. 1 formulierte Passus (S. 6 re. Sp.) beschreibt die Änderung, ohne sie zu begründen. 
betreffen, und sie müssen im Rahmen der Entscheidungskompetenz des Abgeordnetenhauses liegen. Welche Begrenzung ergibt sich aus dem Ersten? Auch Privates oder Privatrechtliches kann das Parlament legitimerweise beschäftigen, und es führt dann zur Bildung eines bestimmten politischen Willens im Parlament. Und was soll das Zweite, die Betroffenheit Berlins, besagen? Gibt es etwas, was Berlin nicht betrifft, aber dennoch in die Zuständigkeit des Abgeordnetenhauses fällt, so daß es notwendig oder angebracht ist, es von einer lokal radizierten Volkskompetenz auszunehmen? Soll vielleicht gesagt werden, daß der Gegenstand nur Berlin, nicht zugleich auch anderes, z.B. Brandenburg, betreffen darf? Schließlich gibt auch das Dritte, die Entscheidungszuständigkeit des Abgeordnetenhauses, Rätsel auf. Wozu die beiden ersten Voraussetzungen, wenn es doch ohnehin nur darauf ankommt, daß das Abgeordnetenhaus, würde es selbst tätig werden wollen, zuständig ist? Und ist nicht diese Zuständigkeit eine ganz und gar selbstverständliche Voraussetzung? Die Regelungen über die Volksgesetzgebungskompetenzen thematisieren sie deswegen regelmäßig gar nicht erst. Die Bündelung derartiger wenig oder nichts besagender und einander überschneidender Voraussetzungen ist, wenn ich meinen Eindruck zusammenfassen darf, zu viel des Guten, wenn es um nicht mehr geht als zu sagen, daß das Volk das beschließen darf, was das Abgeordnetenhaus beschließen darf.

Eines der vielen Worte, die die Verfassung hier macht, birgt freilich die Chance zu einer echten und sinnvollen Begrenzung der Volksbeschlußkompetenz: Wie Mecklenburg-Vorpommern (Art. 59), Nordrhein-Westfalen (Art. 67 a), RheinlandPfalz (Art. 108 a) und Schleswig-Holstein (Art. 41) spricht Art. 62 Abs. 1 Satz 2 VvB von der Entscheidungszuständigkeit des Parlaments, in dessen Rahmen sich der Antrag halten muß. Hätte es nicht, wenn man überhaupt die selbstverständliche Kompetenzgrenze erwähnen wollte, gereicht, von Zuständigkeit zu sprechen? Und wenn das so ist, liegt dann nicht die Annahme nahe, die fünf Verfassungen, die statt dessen das Wort Entscheidungszuständigkeit wählen, täten dies mit Bedacht, um Nichtentscheidungen - wie Empfehlungen, Ersuchen, Loyalitätsbekundungen, Proteste etc. -, für die ein Parlament auch zuständig ist, aus der Volkskompetenz auszuklammern? Sinn ergibt eine solche Annahme, weil sie dem Volk den gewaltigen Aufwand eines Volksbeschlußverfahrens erspart, an dessen Ende eine Entscheidung nicht stehen könnte, sondern allenfalls eine unverbindliche Äußerung in dieser oder jener Richtung. Auch wenn die Parlamentsmaterialien sich hierzu, soweit ich gesehen habe, nicht äußern, halte ich eine solche ressourcenschonende und Enttäuschungen ersparende Auslegung der Verfassung für geboten.

Für sie sprechen auch systematische Gründe: Die Verfassung behandelt Volksbeschlüsse nicht weniger streng als Volksgesetze: Es gelten für beide dieselben Verfahren, Quoren und ${ }^{30}$ Bereichsausnahmen. Das ist verständlich und vertretbar allenfalls, wenn am Ende eines erfolgreichen Volksbeschlußverfahrens eine verbindliche Entscheidung steht.

Das Volksbegehren zur Offenhaltung des Flughafens Tempelhofs war nach alledem mit Art. 62 Abs. 1 Satz 2 VvB von vornherein nicht vereinbar. Das Abgeord-

30 Anders insoweit etwa Rheinland-Pfalz (Art. 108 a Abs. 1 Satz 2). 
netenhaus war nicht zuständig, über die Offenhaltung des Flughafens zu entscheiden; die Entscheidungskompetenz lag allein bei Regierung und Verwaltung. Mehr als eine Empfehlung hätte das Parlament nicht aussprechen können, auf mehr konnte deswegen auch der Volksentscheid, wie seine Initiatoren und die Politik richtig sahen, nicht gehen. Eben deswegen aber war das Begehren unzulässig.

\section{b) Die Bezirksebene: Bürgerbeschlüsse}

2005 trug Berlin zum ersten Mal direktdemokratische Elemente in die Verwaltung, wenngleich nur auf Bezirksebene, hinein. Dem Art. 72 VvB, der die Rechtsstellung und Funktionen der Bezirksverordnetenversammlung behandelte (und im heutigen Absatz 1 weiterhin unverändert behandelt), fügte das Fünfte Änderungsgesetz ${ }^{31}$ einen neuen Absatz 2 an:

„(2) An die Stelle von Beschlüssen der Bezirksverordnetenversammlung können im Rahmen der Zuständigkeit der Bezirksverordnetenversammlung Bürgerentscheide der zur Bezirksverordnetenversammlung Wahlberechtigten treten. Das Nähere wird durch Gesetz geregelt.“

Zugleich erhielt Art. 3 Abs. 1 seine heutige, nicht sonderlich gelungene Gestalt, die auch auf die Neuerungen in Art. 72 VvB verweist. Die Wörter „im Rahmen der Zuständigkeit der Bezirksverordnetenversammlung“ in Art. 72 Abs. 2 VvB erübrigen sich; Bürgerentscheide außerhalb dieser Zuständigkeit könnten kaum ,an die Stelle"von Beschlüssen der Versammlung treten.

Mit der Reform schloß sich Berlin den kommunalrechtlichen Regelungen der anderen Länder an. Ein empfindliches direktdemokratisches Defizit war behoben. ${ }^{32}$ Mit Genugtuung vermerkt man, daß Bereichsausnahmen - insbesondere finanzieller Art - fehlen. Das Schweigen der Verfassung verbietet ihre einfachgesetzliche Einführung. $\S 45$ Abs. 1 Satz 2 Bezirksverwaltungsgesetz, ${ }^{33}$ der in Angelegenheiten des $\S 12$ Abs. 1 Nr. 1 (Bezirkshaushaltsplan; Genehmigung von überund außerplanmäßigen Ausgaben) und Nr. 2 (Verwendung von Sondermitteln der Bezirksverordnetenversammlung) ausschließlich Anträge mit empfehlender oder ersuchender Wirkung zuläßt, erscheint daher bedenklich. Satz 3 des $\S 45$ Abs. 1 (,Bürgerbegehren und Bürgerentscheide sind nicht deswegen unzulässig, weil sie finanzwirksam sind.") wirkt immerhin in wohltuender Weise einer Überdehnung des Satzes 2 entgegen; man wünschte sich für den Haushaltsvorbehalt bei der Volksgesetzgebung Ähnliches.

31 Vom 28. Juni 2005, GVB1. S. 346.

$32 \mathrm{Zu}$ ersten Begehren unter der Neuregelung vgl. die Antwort des Senats vom Februar 2007 auf eine Kleine Anfrage, AH-Drs. 16/10229. Aktuellere Übersicht auf der Website http://bb.-mehrdemokratie.de/buergerbegehren_berlin.html.

33 I.d.F. des Siebenten Gesetzes zur Änderung des Bezirksverwaltungsgesetzes vom 7. Juli 2005, GVB1. S. 390. 
Das Sechste Änderungsgesetz setzte noch im selben Jahr das Wahlalter auf 16 Jahre herab, ${ }^{34}$ so daß Bürgerbegehren und Bürgerentscheid nunmehr allen mindestens sechzehnjährigen Deutschen und ${ }^{35}$ Staatsangehörigen eines anderen Mitgliedstaates der Europäischen Union offen stehen.

Verfahren (einschließlich der Zulässigkeitsprüfung durch Verwaltung und Gerichte) und Quoren müßten im Kern ebenfalls in der Verfassung festgelegt werden, auch wenn die Herstellung einer Zweidrittelmehrheit in diesen Details noch so schwer fällt. Hier besteht Nachholbedarf. Auch sollte (für den augenblicklich eher wahrscheinlichen Fall, daß das obligatorische Verfassungsreferendum nicht auf alle Verfassungsänderungen ausgedehnt wird) Art. 72 Abs. 2 VvB in den Satz 2 des Art. $100 \mathrm{VvB}$ aufgenommen werden. Daß von einem so verstärkten Schutz des Bürgerentscheids auch Nichtdeutsche und Nichtvolljährige profitieren würden, sollte nicht im Wege stehen. ${ }^{36}$

\section{Im Zentrum der direkten Demokratie: Die Volksgesetzgebung}

Den Kernbereich der direkten Demokratie betreten wir mit der Volksgesetzgebung. In Berlin kann das Volk seit 1995 Gesetze beschließen, seit 2006 auch die Verfassung ändern. Zum Ersten haben die Berliner schon öfter angesetzt, ${ }^{37}$ zum Zweiten noch nicht.

\section{1995/2006: Die einfache Gesetzgebung}

Die Überarbeitung der Landesverfassung von 1995 wiederbelebte die Volksgesetzgebungskompetenz, Art. 62, 63 VvB. Daß sie Anklang bei den Berlinern fand, die Art. 101 Abs. 1 Satz 1 VvB erstmals zum Verfassungsreferendum aufrief, ${ }^{38}$ konnte

34 Art. 70 Abs. 1 Satz 2 VvB i.d.F. des Sechsten Änderungsgesetzes vom 27. September 2005, GVB1. S. 494.

35 Gemäß dem unveränderten Satz 3 des Art. 72 Abs. 1 VvB.

36 Es liegt insofern anders als bei Art. $61 \mathrm{VvB}$, der bislang ebenfalls nicht in Art. 100 Satz $2 \mathrm{VvB}$ genannt ist: Die Überflüssigkeit der Vorschrift spricht gegen ihre zusätzliche Absicherung.

37 Übersicht über 21 Verfahren auf der Website http://bb.mehr-demokratie.de/uebersicht_volksbegehren.html. - Das Kita-Volksbegehren (,Kitakinder + Bildung von Anfang an $=\bar{G}$ ewinn für Berlin") hatte insofern Erfolg, als der Verfassungsgerichtshof des Landes Berlin am 6. Oktober 2009 - VerfGH 143/08 - (http:// www.berlin.de / imperia / md / content / senatsverwaltungen / justiz / gerichte / verfassungsgerichtshof / urteil _verfgh_143_08.pdf ?start $\&$ ts $=1254819580$ ) urteilte, es verstoße trotz seiner erheblichen finanziellen Auswirkung nicht gegen Art. 62 Abs. 2 VvB (,Landeshaushaltsgesetz“), und der Senat sich daraufhin sein Anliegen weitgehend zu eigen machte (vgl. Pressemitteilung des Senats vom 27. Oktober 2009, http://www. berlin.de/ landespressestelle/archiv/2009/10/27/143776/index.html), so daß es nicht weiter verfolgt zu werden braucht.

38 Die - angemessene - Geste war für das Parlament und den Senat risikolos. Alle Verfassungsänderungen, an denen ihnen besonders lag, waren noch kurz vor der Überarbeitung beschlossen 
nicht überraschen. Allerdings waren die Quoren hoch und die Fristen kurz. Aber der Anschluß an die sich in den anderen Ländern entwickelnde direkte Demokratie war doch geschafft. Einzelheiten der damaligen Regelung sollen an dieser Stelle nicht interessieren, weil sie dank der achten Änderung der überarbeiteten Verfassung im Jahre 2006 weithin überholt sind. Nicht ohne berechtigten Stolz führten die Fraktionen des Abgeordnetenhauses, die sämtlich die Änderung geschlossen trugen, in ihrer Begründung des Entwurfs ${ }^{39}$ aus:

„Die Erweiterung der Volksgesetzgebung auf Landesebene knüpft an die Einführung des Bürgerentscheids auf Bezirksebene an. Es wird mehr direkte Demokratie in Ergänzung der parlamentarischen Demokratie ermöglicht. Sämtliche Hürden für die Volksgesetzgebung werden abgesenkt: Die Anzahl der notwendigen Unterstützungsunterschriften, die Quoren für das Volksbegehren und für den Volksentscheid. Außerdem werden die Verfahren volksbegehrensfreundlicher, indem die Frist für das Volksbegehren verdoppelt wird. Es wird zudem leichter, Volksentscheide an einem Wahltag oder mehrere Volksentscheide gleichzeitig durchzuführen. Damit kann eine höhere Beteiligung erreicht werden. Zur weiteren Verfahrenserleichterung sind Änderungen des Gesetzes über Volksinitiative, Volksbegehren und Volksentscheid geplant.“

Der Blick richtet sich dementsprechend allein auf das seit 2006 geltende Verfassungsrecht, und zwar an dieser Stelle nur, soweit es um den Erlaß, die Änderung oder Aufhebung einfacher Gesetze geht. Wenn wir aus Art. 62, $63 \mathrm{VvB}$ die nicht hierher gehörenden, weil nicht die Gesetzgebung betreffenden Fremdkörper aussondern, bietet sich folgendes Bild der Volksgesetzgebung: ${ }^{40}$

\section{a) Die Einräumung der Gesetzgebungskompetenz}

Art. $62 \mathrm{Abs}$. $1 \mathrm{Satz} 1 \mathrm{VvB}$ gewährt die Kompetenz zur Volksgesetzgebung. Anders als Art. 61 Abs. 1 Satz 1 VvB nennt er dabei nicht die Träger der Kompetenz; von ihnen - den ,zum Abgeordnetenhaus Wahlberechtigten“41 - spricht erst Art. 63 VvB. Das Wort Volksbegehren, mit dem Art. 62 Abs. 1 Satz 1 VvB beginnt, läßt allerdings schon ahnen, daß es um das Berliner Staatsvolk geht. Gerade weil es insofern anders als bei der Initiative nach Art. $61 \mathrm{VvB}$ liegt, würde sich empfehlen, dies in Art. $62 \mathrm{VvB}$ von Beginn an klarzustellen, etwa mit der Formulierung: „Alle

worden und in Kraft. Hätten die Berliner die Überarbeitung abgelehnt, wäre man mit der nicht überarbeiteten Fassung gut ausgekommen.

39 AH-Drs. 15/5038, S. 6 li. Sp.

40 Die Aufteilung der Materie auf zwei Artikel und überschaubare Absätze ist leserfreundlich. Dabei sollte es auch dann bleiben, wenn man sich entschließt, aus Art. 62, 63 VvB das nicht zur „Gesetzgebung“ Gehörende zu entfernen. Redaktionell abschreckendes Beispiel: Art. 50 der hamburgischen Verfassung.

41 Gemeint sind hier und anderswo (z.B. in Art. 63 Abs. 1-3 VvB) die „Abgeordnetenhauswahlberechtigten“ (oder die ,zur Abgeordnetenhauswahl Berechtigten“). 
zum Abgeordnetenhaus Wahlberechtigten haben das Recht, im Wege des Volksbegehrens und Volksentscheides Landesgesetze zu erlassen, zu ändern oder aufzuheben.“

Der vorsorgliche Zusatz des Art. 62 Abs. 1 Satz 1 VvB ,soweit das Land Berlin die Gesetzgebungskompetenz hat" ist unschädlich, aber überflüssig. Er findet sich ja bei der Parlamentsgesetzgebung, Art. 59, $60 \mathrm{VvB}$, auch nicht; würde deswegen jemand auf die Idee kommen, das Abgeordnetenhaus dürfte Bundesgesetze oder brandenburgische Gesetze erlassen, ändern oder aufheben?

\section{b) Die zeitliche Begrenzung des Initiativrechts}

Art. 62 Abs. 1 Satz 3 VvB, der sich auch ${ }^{42}$ auf Satz 1 bezieht, schmälert die eingangs eingeräumte Kompetenz beträchtlich: Innerhalb einer (nach Art. 54 Abs. 1 Satz 1 VvB fünf Jahre währenden) Wahlperiode ist ein Volksbegehren ,zu einem Thema“ nur einmal zulässig. Die Einschränkung findet sich, wenn ich recht sehe, in keiner anderen deutschen Verfassung. Welchen Sinn soll sie haben? Warum soll eine (in irgendeinem Stadium) erfolglose Initiative nicht zeitnah - von denselben oder anderen - wieder aufgegriffen, ${ }^{43}$ warum eine erfolgreiche nicht zeitnah - von anderen ${ }^{44}$ - angegriffen werden dürfen? Warum kommt es auf die Wahlperiode an? Ist sie noch jung, kann ein erneutes Begehren mehrere Jahre lang nicht unternommen werden, neigt sie sich dem Ende zu, ist nichts verloren. ${ }^{45}$ Geht es darum, das jeweils gegenwärtige Abgeordnetenhaus vor einer Überflutung mit Anträgen (die es ja zu nichts außer zur vorübergehenden Befassung verpflichten) zu schützen? Für derartige Sorgen sind die Quoren und eine vernünftige Politik zuständig. Jedes Wiederholungsverbot hat etwas Kleinkariertes; nicht ohne Grund gilt derartiges auch innerhalb des Parlaments nicht, obwohl zur Gängelung der Opposition und der Querulanten in den eigenen Reihen vielleicht nicht ganz ungeeignet.

Und wer sich an all diesen Fragen nicht stört oder kluge Antworten auf sie weiß, müßte noch sagen können, was ein „Thema“ ist. ${ }^{46}$ Wie sähe es z.B. mit einem neuen Begehren aus, das die Verbesserungen im Kita-Bereich, die von dem aktuellen KitaBegehren angestrebt wurden, intensivieren, vermehren oder verändern möchte? Ist das „Thema“ Kita oder was? Oder nehmen wir an, zum laufenden Volksbegehren „Mehr Demokratie beim Wählen“ gesellte sich ein anderes Begehren zum Abge-

42 Bis 2006 (als Satz 2) nur.

43 Das speziellere Wiederholungsverbot des Art. 73 Abs. 2 der sächsischen Verfassung (gescheiterter Volksentscheid) mag noch Sinn ergeben.

44 Auch das Abgeordnetenhaus selbst muß ja keine Schamfrist einhalten.

45 Eine fixe Zahl von Jahren - z.B. 2,5 (um die Mitte einer Berliner Wahlperiode zu nehmen) vermiede diese Diskriminierungen, wäre aber in jeder sonstigen Hinsicht nicht weniger unangemessen.

46 Leichter macht es einem auch insofern Art. 73 Abs. 2 der sächsischen Verfassung, nach dem der gescheiterte „Volksantrag“ nicht wiederholt werden darf. Da weiß man ungefähr, woran man ist, weil es sich offenbar um den gleichen Antrag handeln muß. Auch hier wird man allerdings rasch zu der Frage gelangen, ob es genügt, daß der zweite dem ersten im wesentlichen gleicht und was an diesem ,wesentlich“ war. 
ordnetenhauswahlrecht, das einzelnes - z.B. die dort vorgesehene Ersatzstimme streicht oder weiteres hinzufügt oder ganz anderes im Wahlrecht reformieren will? Sind vielleicht Themen gemeint, wie Absatz 2 sie anspricht? Ich plädiere für Streichung des Satzes 3.

\section{c) Die thematische Begrenzung des Initiativrechts}

Art. 62 Abs. $2 V v B$ fügt weitere, thematische Schranken hinzu, die so oder ähnlich in allen Landesverfassungen auftauchen: ${ }^{47}$

„Volksbegehren zum Landeshaushaltsgesetz, zu Dienst- und Versorgungsbezügen, Abgaben, Tarifen der öffentlichen Unternehmen sowie zu Personalentscheidungen sind unzulässig.“

Finanziell traut die Verfassung den Berlinern also nicht so recht über den Weg. Sie rechnet mit Unvernunft, Parteilichkeit und Neid und sucht ihnen - ohne zwischen Ausgaben und Einnahmen zu unterscheiden - auf ausgewählten Gebieten vorzubeugen. Ihr Mißtrauen geht allerdings nicht so weit, daß sie alle Projekte, die nennenswerte Ausgaben oder Einnahmen mit sich bringen können, verbietet; insofern ist sie nicht so skeptisch wie etwa das Saarland (Art. 99 Abs. 1 Satz 3: „finanzwirksame Gesetze“) oder Nordrhein-Westfalen (Art. 68 Abs. 1 Satz 4: „Finanzfragen“) und Rheinland-Pfalz (Art. 108 a Abs. 1 Satz 2, 109 Abs. 3 Satz 3: „Finanzfragen“). Optimistisch ist sie insofern, als sie die Diäten der Abgeordneten nicht einbezieht.

Die „Personalentscheidungen“ fallen etwas aus dem Rahmen, ${ }^{48}$ auch wenn man unterstellen darf, daß es um Entscheidungen nur über öffentliches Personal geht: Wann je sollen Personalentscheidungen Gegenstand von Gesetzen sein? Und gibt es nicht eine Fülle von Personalentscheidungen, die sich finanziell gar nicht auswirken?

Ungeachtet dessen gibt das Nebeneinander der fünf Bereiche Aufschluß über die Auslegung des ersten Bereiches, des „Landeshaushaltsgesetzes“: Regelungen in allen fünf Bereichen sind geldwert, aber sonstige geldwerte Sektoren sind nicht aufgezählt. Das spricht dafür, jeden Bereich als speziellen anzusehen und nicht dadurch aufzublähen, daß ihm Einnahmen und Ausgaben aus nicht genannten Bereichen zugeschlagen werden. „Landeshaushaltsgesetz“ muß deswegen genauso speziell verstanden werden wie z.B. „Dienst- und Versorgungsbezüge“. Hinzu kommt, daß sich die Aufzählung der vier letzten Bereiche erübrigen würde, wenn man „Haushaltsgesetz“ mit „Haushalt“ und diesen wiederum mit „finanzwirksamen Gesetz“ gleich-

47 Baden-Württemberg Art. 60 Abs. 6, Bayern Art. 73, Brandenburg Art. 76 Abs. 2, Bremen Art. 70 Abs. 2, Hamburg Art. 50 Abs. 1 Satz 2, Hessen Art. 124 Abs. 1 Satz 3, MecklenburgVorpommern Art. 60 Abs. 2 Satz 1, Niedersachsen Art. 48 Abs. 1 Satz 3, Nordrhein-Westfalen Art. 68 Abs. 1 Satz 4, Rheinland-Pfalz Art. 108 a Abs. 1 Satz 2, 109 Abs. 3 Satz 3, Saarland Art. 99 Abs. 1 Satz 3, Sachsen Art. 73 Abs. 1, Sachsen-Anhalt Art. 81 Abs. 1 Satz 3, Schleswig-Holstein Art. 41 Abs. 2, Thüringen Art. 82 Abs. 2.

48 Außer Berlin nennen sie nur Brandenburg (Art. 76 Abs. 2), Bremen (Art. 87 Abs. 2 Satz 2) und Thüringen (Art. 68 Abs. 2, 82 Abs. 2). 
stellen würde. Volksbegehren „zum“Landeshaushaltsgesetz sind deswegen nur solche, die - um mit Art. 62 Abs. 1 Satz 1 VvB zu sprechen - darauf gerichtet sind, das (jeweilige) Landeshaushaltsgesetz zu erlassen, zu ändern oder aufzuheben. Es geht allein um Haushaltsgesetzentwürfe oder um Entwürfe zur Änderung oder Aufhebung des Haushaltsgesetzes. Derartige Begehren wird es nicht geben. Deswegen könnte der Passus, wenn nicht der gesamte Absatz 2, ohne Schaden gestrichen werden; das Abgeordnetenhaus sollte nicht darauf warten, daß ihm eine Verfassungsinitiative damit zuvorkommt.

Es kommt nach dieser Lesart also nicht darauf an, daß ein Entwurf, der einem Begehren zugrunde liegt, etwa zur Änderung des Haushaltsgesetzes Anlaß geben könnte, weil die von ihm vorgesehenen Ausgaben oder Einnahmen noch in einen bestehenden Haushaltsplan eingepaßt werden müßten. Das wäre kein Begehren zum Haushaltsgesetz. Will man auch solche Entwürfe verhindern, muß man die „finanzwirksamen" Begehren in den Art. 62 Abs. 2 VvB hineinnehmen. Froh wird man damit nicht werden, weil es engherzig und Streit über die Grenze zwischen finanzneutralen und finanzwirksamen Vorhaben unvermeidlich ist.

Dem Vorwurf der Engherzigkeit (wenngleich vielleicht nicht allen begrifflichen Schwierigkeiten) entgeht man, wenn man finanzwirksame Begehren nicht verbietet, sondern ausdrücklich formulierte Anforderungen an sie stellt. Art. 90 Abs. 1 VvB läßt Vorlagen und Anträge über Maßnahmen, die eine Minderung der Einnahmen oder eine Erhöhung der Ausgaben gegenüber dem Haushaltsplan zur Folge haben, $\mathrm{zu}$, doch müssen die Beschlüsse über sie „Bestimmungen über die Deckung enthalten“, Art. 90 Abs. 2 VvB. Nach dem bislang geltenden Recht steht Art. 90 VvB dem Volksgesetzgeber nicht zur Verfügung. ${ }^{49}$ Aber das heißt nicht, daß es ihm nicht durch Verfassungsänderung zur Obliegenheit gemacht werden kann. Eine vergleichbare Regelung stand vor über einem halben Jahrhundert schon einmal auf der Tagesordnung: 1953 und 1955 bemühte sich der Senat von Berlin um einfachgesetzliche Ausführungsbestimmungen zu den direktdemokratischen Regelungen der Verfassung von 1950. Er übernahm die Bereichsausnahmen des Art. 49 Abs. 5 VvB 1950 („Haushaltsplan, Abgabengesetze sowie Lohn- und Gehaltsregelungen können nicht Gegenstand eines Volksbegehrens sein“) und fügte hinzu: ${ }^{50}$

49 Das bemerkt VerfGH, Urteil vom 6. Oktober 2009, VerfGH 143/08, http://www.berlin.de/ imperia/md/content/senatsverwaltungen/justiz/gerichte/verfassungsgerichtshof/urteil_verfgh 143_08.pdf?start\&ts=1254819580, S. 22, 23, zu Recht.

50 1953: $\S 3$ Abs. 2 Satz 2 des Entwurfs eines Gesetzes über Volksbegehren und Volksentscheid, AH-Drs. I/2039, S. 1. Die Begründung (,Absatz 2 entspricht der Vorschrift des Artikels 49 Abs. 5 der Verfassung“, S. 4 li. Sp. unten) konnte allerdings nicht Satz 2, sondern nur den vorangehenden Satz 1 des $\S 3$ Abs. 2 meinen, stellt das Licht der Autoren also unter den Scheffel. - 1955: gleichlautend $\S 3$ Abs. 3 des Entwurfs, AH-Drs. II/157, S. 1. Diesmal mit aussagekräftigerer Begründung: „Absatz 3 beruht auf der Vorschrift des Artikels 78 Abs. 2 der Verfassung“" (ebenda S. 7 re. Sp.). Art. 78 Abs. 2 VvB 1950 entspricht wörtlich dem heutigen Art. 90 Abs. 2 VvB. - In der Sprache heutiger Parlamentsgeschäftsordnungen geht es um „Finanzvorlagen“ (§96 BTGeschO) oder Vorlagen mit „haushaltsmäßiger Auswirkung“ (§ 37 AHGeschO). 
„Ein Volksbegehren ist auch dann unzulässig, wenn sein Gegenstand Ausgaben erfordert, die im Haushaltsplan nicht vorgesehen sind, es sei denn, daß zugleich auch Bestimmungen über die Deckung zum Gegenstand des Volksbegehrens gemacht werden.“

Mit einer einfachgesetzlichen Regelung würde man sich heute wohl nicht begnügen wollen; aber inhaltlich hat der Vorschlag nichts von seiner Angemessenheit verloren.

Besorgt man eine Überforderung der Initiatoren durch derartigen Aufwand, will aber finanzwirksame Begehren (die nicht das Haushaltsgesetz im oben beschriebenen strengen Sinne erlassen, ändern oder aufheben) auch nicht ausschließen, bleibt nur eine Klarstellung nach Art des $§ 45$ Abs. 1 Satz 3 Bezirksverwaltungsgesetz:

„Volksbegehren sind nicht deswegen unzulässig, weil sie finanzwirksam sind.“

Auch sie würde in die Verfassung gehören. Beide Änderungen würden der Deutung des geltenden Haushaltsvorbehalts in Art. 62 Abs. 2 VvB durch den Verfassungsgerichtshof des Landes Berlin den Boden entziehen. Nach ihr gilt der Vorbehalt zwar auch für Begehren, die keine Haushaltsgesetze sind, aber, weil finanzwirksam, auf sie einwirken und ihre Anpassung erfordern - aber nur dann, wenn sie das zum Zeitpunkt des Zustandekommens des Volksgesetzes geltende Haushaltsgesetz berühren. Dagegen erstrecke er sich nicht auf finanzwirksame Volksgesetze, die sich nur auf künftige Haushaltsgesetze auswirkten. ${ }^{51}$

\section{d) Das hinreichend unterstützte Volksbegehren}

Art. 62 Abs. 3, 63 Abs. 1 Satz 1 VvB unterrichten über die Unterstützung, die ein Volksbegehren braucht, und das Verfahren vor der Durchführung des Begehrens. 20000 zum Abgeordnetenhaus Wahlberechtigte müssen das Anliegen durch ihre Unterschrift unterstützen, Art. 63 Abs. 1 Satz 1 VvB, eine Zahl, die ausreichend, wohl aber auch nötig ist, um die Ernsthaftigkeit und das Gewicht des Begehrens, die allein den späteren Aufwand rechtfertigen können, zu indizieren.

Der Senat hat den Entwurf ,unter Darlegung seines Standpunktes dem Abgeordnetenhaus zu unterbreiten, sobald der Nachweis der Unterstützung des Volksbegehrens erbracht ist“, Art. 62 Abs. 3 Satz 1 VvB. Der Entwurf ist also mit den Unterschriften beim Senat einzureichen. Das Wort „,sobald“ drängt zu einer gewissen Zügigkeit, doch muß angemessene Zeit bleiben, den Standpunkt zu entwickeln und zu formulieren. Politisch motiviertes Hinhalten erwartet und gestattet die Verfassung nicht.

51 VerfGH (Fn. 49), S. 16-24. - Damit war das Kita-Volksbegehren freilich noch nicht gerettet, denn mangels ausdrücklicher Bestimmung des Inkrafttretens bedurfte es noch der verfassungskonformen Deutung (VerfGH [Fn. 49], S. 30 f.), das Begehren wolle ein Inkrafttreten des Volksgesetzes ,erst zu Beginn des nächsten Haushaltsjahres ..., das auf einen erfolgreichen Volksentscheid folgt“". Der Kunstgriff wäre nicht nötig gewesen, hätte der Gerichtshof den Haushaltsvorbehalt so eng gedeutet, wie hier vorgeschlagen. 
Die Stellungnahme des Senats soll, wie immer sie ausfällt, dem Abgeordnetenhaus die Entscheidung erleichtern, ob es sich das Begehren zu eigen macht oder nicht. Für diese Überlegung räumt Art. 62 Abs. 3 Satz 2 VvB eine - angemessene viermonatige Frist ein. Nimmt das Abgeordnetenhaus den Entwurf ,inhaltlich in seinem wesentlichen Bestand unverändert" 52 an (Art. 62 Abs. 3 Satz 2 VvB), so ist das Verfahren beendet. Tut es dies nicht, hängt es von den Initiatoren ab, ob sie ihr Begehren durchführen lassen wollen (Art. 62 Abs. 3 Satz 2 VvB). Eine Frist, sich so oder so zu entscheiden, setzt ihnen die Verfassung nicht, ebensowenig dem Land, sollten sie sich für die Durchführung entscheiden.

$\mathrm{Ob}$ in dieser oder einer sich ggf. anschließenden Phase des Verfahrens das Abgeordnetenhaus eine Pflicht hat, eigene Vorkehrungen und Entscheidungen im Themenbereich des Begehrens zurückzustellen, zu ändern oder aufzugeben, sagt die Verfassung nicht. Je weiter das Verfahren fortschreitet, um so mehr bietet sich die Verfassungsorgantreue als - freilich höchst ungewisses, weil ungeschriebenes - Regulativ an. Geschriebenes Verfassungsrecht wäre mir auch hier lieber.

Die große Schwäche des Art. 62 Abs. 3 VvB liegt darin, daß er das in diesem Verfahrensstadium Wichtigste verschweigt: Nach § 17 Abs. 1 AbstG prüft zunächst die Senatsinnenverwaltung die Übereinstimmung des Antrags mit Art. 62 Abs. 1 und 2 VvB sowie $\S \S 10-16$ AbstG. Sodann geht die Sache an den Senat: „Ist das Volksbegehren nach Artikel 62 Abs. 2 der Verfassung von Berlin unzulässig oder entspricht es nicht den Anforderungen der $\S \S 10$ bis $16,{ }^{53}$ so stellt der Senat dies durch Beschluß ausdrücklich fest. Die Entscheidung ist zu begründen und den Vertrauenspersonen und dem Abgeordnetenhaus mitzuteilen“. Was aus einer solchen Feststellung folgt, sagt das Gesetz nicht. Daß das Abgeordnetenhaus einen vom Senat als verfassungs- und/oder gesetzeswidrig angesehenen Entwurf nicht übernehmen wird, liegt nahe. Aber was geschieht mit ihm sonst? Können die Initiatoren das Verfahren dann weiterbetreiben? $§ 18$ AbstG, der die Fortsetzung des Verfahrens regelt, schweigt ebenso wie $\S 17$. Nach $\S 41$ Abs. 1 AbstG können die Initiatoren („oder ein Viertel der Mitglieder des Abgeordnetenhauses“ [?]) u.a. gegen die Entscheidung des Senats nach $\S 17$ Abs. 5 Einspruch beim Verfassungsgerichtshof des Landes Berlin erheben. Aber was, wenn sie es nicht tun? Und wenn sie es tun, ruht dann das Gesetzgebungsverfahren automatisch und in jedem Falle bis zur Entscheidung des Gerichts? In der Praxis wird es so gehandhabt; vernünftig ist es, aber im Gesetz steht es (anders als z.B. in Hamburg Art. 50 Abs. 6 Satz 2; vgl. auch Sachsen Art. 71 Abs. 2 Satz 4) nicht.

Schwerer als diese Schwäche der einfachgesetzlichen Regelung wiegt das Schweigen der Verfassung. Sie läßt mit keinem Wort erkennen, daß es in dieser Phase eine Senatsentscheidung geben kann, die das Verfahren praktisch anhält und die Initiatoren, wollen sie es fortsetzen, zuvor zur Anrufung des Verfassungsgerichtshofs zwingt. Auch Art. 84 Abs. 2 VvB, der Zuständigkeiten des Verfassungs-

52 Dieselben Tatbestandsmerkmale auch in Art. 62 Abs. 4 Satz 4 VvB (vgl. unten sub e).

53 Wobei $\S 11$ Abs. 1 AbstG den in $\S 17$ Abs. 5 AbstG nicht genannten Absatz 1 des Art. 62 VvB zitiert und nennt und $\S 12 \mathrm{Abs} .1 \mathrm{AbstG}$ mit dem bereits in $\S 17 \mathrm{Abs}$. 5 AbstG genannten Absatz 2 des Art. $62 \mathrm{VvB}$ ebenso verfährt. Hier läßt sich einiges noch redaktionell bereinigen. 
gerichtshofs aufzählt, verrät nichts. Das ist umso bedauerlicher, als die praktische Handhabung durchaus dem Interesse aller Beteiligten entspricht, frühzeitig zu erfahren, ob das Begehren den spezifischen Anforderungen des Volksgesetzgebungsverfahrens entspricht. Die Zuständigkeit des Gerichts ist verfassungsrechtlich durch Art. 84 Abs. 2 Nr. 6 VvB gedeckt; für die Entscheidungszuständigkeit des Senats und ihre Folgen findet sich in der Verfassung kein Anhalt.

Es empfiehlt sich dringend, dem Vorbild von neun anderen Landesverfassungen $^{54} \mathrm{zu}$ folgen, welche die hier angesprochenen Fragen - knapp - thematisieren. Art. 62 Abs. 3 wäre der primäre Standort. Dabei müßte auch deutlich gesagt werden, anhand welcher Maßstäbe zunächst der Senat, später der Verfassungsgerichtshof die „Zulässigkeit“ des Begehrens zu prüfen hätte. Die Urteile des Verfassungsgerichtshofs des Landes Berlin vom 6. Oktober 2009 nennen - wie der Sache nach $\S 17$ Abs. 5 AbstG - Art. 62 Abs. 1 und 2 VvB sowie $\S \S 10-16$ AbstG. ${ }^{55}$ Vor der Änderung 2008 hatte $\S 17$ Abs. 4 S. 3 Nr. 2 AbstG den Senat noch befugt und verpflichtet, überdies zu prüfen, ob das Begehren „,dem Grundgesetz, sonstigem Bundesrecht oder der Verfassung von Berlin ${ }^{56}$ nicht widerspricht“. Der Gerichtshof nahm die Streichung dieser Passage beim Wort und ließ die dort genannten Maßstäbe nicht mehr zu. ${ }^{57} \mathrm{Da}$ er nicht zu erkennen gegeben hat, daß eine umfassende Prüfung (wie sie einfachgesetzlich bis 2008 noch vorgesehen war) verfassungsrechtlich bedenklich sein könnte, ist der Landesgesetzgeber frei, sie wieder einzuführen, nun aber tunlichst auch auf Verfassungsebene. Er könnte es aber auch bei der begrenzten Prüfung, die der Gerichtshof nach der derzeitigen Lage zugelassen hat, belassen, denn die Urteile stellen klar, daß die Begrenzung auch vor höherem Recht Bestand hat.

54 Brandenburg Art. 77 Abs. 2, Hamburg Art. 50 Abs. 6, 65 Abs. 3 Nr. 5, Mecklenburg-Vorpommern Art. 53 Nr. 3, 60 Abs. 2 Satz 2, Niedersachsen Art. 48 Abs. 2, 54 Nr. 2, Nordrhein-Westfalen Art. 68 Abs. 1 Sätze 5 und 6, Saarland Art. 99 Abs. 3, Sachsen Art. 71 Abs. 2 Sätze 2-4, Sachsen-Anhalt Art. 75 Nr. 2, 81 Abs. 2 Satz 1, Schleswig-Holstein Art. 42 Abs. 1 Sätze 3 und 4, Thüringen Art. 80 Abs. 1 Nr. 6, 82 Abs. 3 Satz 2.

55 VerfGH 63/08, http://www.berlin.de/imperia/md/content/senatsverwaltungen/justiz/gerichte/ verfassungsgerichtshof/ urteil_verfgh_63_08.pdf?start\&ts=1254819580, S. 12-17; VerfGH 143/08 (Fn. 49), S. 15 f.

56 „... im übrigen“, mußte man wohl hinzufügen, weil Nr. 1 des $\S 17$ Abs. 4 Satz 3 AbstG Art. 62 Abs. 1, 3 und 5 VvB bereits nannte.

57 Damit konnten maßgebliche Aspekte des Volksbegehrens des „Berliner Wassertischs“ nicht geprüft werden (vgl. VerfGH, 63/08 [Fn. 55], S. 17-31). Sollte das Begehren weiterverfolgt werden und mit einem erfolgreichen Volksentscheid enden, könnten sie z.B. in einem Normenkontrollverfahren wieder zur Sprache kommen. - Ähnliches gilt für das Volksbegehren „Mehr Demokratie beim Wählen“. Über den Einspruch seiner Initiatoren gegen die Feststellung der teilweisen Unzulässigkeit durch den Senat hat der Gerichtshof noch nicht entschieden. Da sich die Feststellung maßgeblich auf die Landesverfassung außerhalb des Art. 62 stützte, nach den Urteilen vom 6. Oktober 2009 aber feststeht, daß der Prüfungsmaßstab ein sehr viel engerer als angenommen ist, könnte es sein, daß das Volksbegehren - mit oder ohne Urteil des Gerichtshofs - weitergeführt werden kann und wird. Auch dann wäre auf die materiellrechtlichen Verfassungsbedenken (insbesondere aus Art. 39 VvB) ggf. später zurückzukommen. Verf. ist in dem Verfahren als Prozeßbevollmächtigter des Senats tätig. 
Bei der Gelegenheit wäre zu überlegen, ob es nicht atmosphärisch günstiger wäre, von dem einfachgesetzlichen Berliner Modell ${ }^{58}$ - erst Regierungsentscheidung, dann Rechtsschutz - abzugehen und die Entscheidung über die Zulässigkeit des Begehrens von vornherein auf den Verfassungsgerichtshof zu übertragen und dem Senat, vielleicht auch dem Abgeordnetenhaus, das Antragsrecht einzuräumen. Dem wachsenden Gewicht der direkten Demokratie in Berlin entspräche es, den Zuständigkeitskatalog des Art. 84 Abs. 2 VvB entsprechend zu ergänzen.

\section{e) Zustandekommen des Volksbegehrens und Annahme durch Volksentscheid}

Das Volksbegehren „kommt zustande“, wenn ihm „mindestens 7 vom Hundert der zum Abgeordnetenhaus Wahlberechtigten innerhalb von vier Monaten ... zu stimmt", Art. 63 Abs. 1 Satz 2 VvB. Quorum und Frist erscheinen fair, sofern angemessene Vorkehrungen für die Stimmabgabe getroffen werden. Zu ihnen bestimmt die Verfassung nichts, wohl aber das von Art. 63 Abs. 4 VvB für das „Nähere“ vorgesehene Gesetz Ausreichendes ( $\S 18-28$ AbstG).

Art. $62 \mathrm{Abs} .4$ und 5, $63 \mathrm{Abs} .1 \mathrm{Satz} 3 \mathrm{VvB}$ behandeln die letzte Etappe, den Volksentscheid. Er wird herbeigeführt werden, wenn das Volksbegehren zustande gekommen ist, Art. 62 Abs. 4 Satz $1 \mathrm{VvB}$, freilich nur dann, wenn nicht das Abgeordnetenhaus den Entwurf ,inhaltlich in seinem wesentlichen Bestand unverändert annimmt“, Art. 62 Abs. 4 Satz 4 VvB. Streit über das, was den ,wesentlichen Inhalt“ ausmacht, ist programmiert, aber wohl auch bei anderer Wortwahl kaum sicher vermeidbar.

Die Verfassung läßt nicht erkennen, daß es die Initiatoren jetzt noch in der Hand hätten, das Verfahren auf sich beruhen zu lassen und auf einen Entscheid (oder gar auf das Parlamentsgesetz) zu ,verzichten“.

Die Regelfrist von vier Monaten für die Herbeiführung des Volksentscheides, Art. 62 Abs. 4 Satz 1 VvB, ,kann auf bis zu acht Monate verlängert werden, wenn dadurch der Volksentscheid gemeinsam mit Wahlen oder mit anderen Volksentscheiden durchgeführt werden kann“, Art. 62 Abs. 4 Satz 2 VvB. Eine solche Zusammenlegung ist vernünftig; sie spart Kosten und läßt eine höhere Abstimmungsbeteiligung erwarten. Die erste Gelegenheit dazu - anläßlich des Volksentscheids „Pro Reli“" - hat die Politik verstreichen lassen. Subjektive Rechte werden dadurch nicht verletzt. Die Initiatoren sollten im Gegenteil in aller Regel Wert auf eine zeitnahe Durchführung des Volksentscheides legen, um den Impetus des erfolgreichen Volksbegehrens in die letzte Phase eines ermattenden Verfahrens hinüberzuretten.

Das begehrte Gesetz ist durch Volksentscheid angenommen, „wenn eine Mehrheit der Teilnehmer und zugleich mindestens ein Viertel der zum Abgeordnetenhaus Wahlberechtigten zustimmt“", Art. 63 Abs. 1 Satz 3 VvB. Das läuft auf ein Beteiligungsquorum von mindestens $25 \%$ hinaus. Das scheint mir, wenn ich es mit den Anforderungen an die Beschlußfähigkeit des Abgeordnetenhauses, Art. 43 Abs. 1

58 Das sonst - bereits auf verfassungsrechtlicher Ebene - wohl nur Nordrhein-Westfalen, das Saarland und Sachsen-Anhalt (vgl. jeweils Fn. 54) kennen. 
$\mathrm{VvB}$, vergleiche, nicht unfair. Hier wie an allen anderen einschlägigen Stellen könnte deutlicher werden, ob es auf das Verhältnis nur der gültigen Ja- und Nein-Stimmen ankommt.

„Der Präsident des Abgeordnetenhauses fertigt das durch Volksentscheid zustande gekommene Gesetz aus; der Regierende Bürgermeister verkündet es im Gesetzund Verordnungsblatt für Berlin“, belehrt uns Art. 62 Abs. 5 VvB. Nichts anderes hätten wir erwartet - aber warum heißt es von den Parlamentsgesetzen in Art. 60 Abs. $2 \mathrm{VvB}$, daß sie unverzüglich auszufertigen und sodann binnen zwei Wochen zu verkünden sind? Beide Regelungen gehören, so gebietet es der Respekt vor Volksgesetzen, vereinheitlicht und, so legt es das Handwerk nahe, zusammengefaßt und hinter Art. 63 VvB plaziert. Bei der Gelegenheit sollte wohl auch das Inkrafttreten von Volksgesetzen thematisiert und ebenso wie das von Parlamentsgesetzen, Art. 60 Abs. 3 VvB, jedenfalls in seiner Nachbarschaft, geregelt werden.

Von einer Karenzzeit, innerhalb deren das Volksgesetz jedenfalls durch Parlamentsgesetz nicht abänderbar ist, weiß die Verfassung nichts. Es gibt sie nicht. Was die Verfassungsorgantreue dennoch erlauben oder gebieten könnte, ist, wie alles Ungeschriebene, außer für die Verfassungsgerichte höchst ungewiß.

\section{Verfassungsänderungen}

Seit 1995 beteiligt Berlin das Volk an Änderungen der Art. 62, 63, die den Kern der Volksabstimmungskompetenzen enthalten. Seit 2006 läßt es überdies Verfassungsinitiativen zu. Das Erste ist gut, aber zu wenig, das Zweite angemessen und überfällig.

Redaktionell ist zu beanstanden, daß beides getrennt behandelt wird. Verfassungsänderung ist Gesetzgebung und gehört dementsprechend in den Abschnitt V. Das gilt auch für die Verfassungsänderungen, an denen das Abgeordnetenhaus allein oder auch beteiligt ist, also solche, die nach Art. 100 Satz 1 VvB allein dem Abgeordnetenhaus obliegen oder nach dessen Satz 2 zusätzlich durch Referendum bestätigt werden müssen. Die Verfassungsinitiative ist bereits am richtigen Ort; Art. 100 gehört umgesiedelt.

\section{a) 1995: Verfassungsreferendum}

$\mathrm{Da} ß$ er es mit der Stärkung der direkten Demokratie ernst meinte, zeigte der verfassungsändernde Gesetzgeber 1995 mit dem Satz 2, den er dem (unveränderten) Art. 100 Satz $1 \mathrm{VvB}^{59}$ anfügte:

59 „Änderungen der Verfassung erfordern eine Mehrheit von zwei Dritteln der gewählten Mitglieder des Abgeordnetenhauses." Bei der - oder späterer - Gelegenheit hätte man darauf stoßen können, daß das Adjektiv „,gewählte“ - wie in Art. 43 Abs. 1, 57 Abs. 3 Satz 1 VvB spätestens seit der deutschen Einigung überholt ist, weil heute alle Abgeordneten gewählt sind, selbst die, die sich auf Ausgleichsmandate stützen. - Anfangs lag das noch anders: Art. 25 
„Ist die Verfassungsänderung auf eine Änderung der Artikel 62 und $^{60} 63$ gerichtet, so bedarf es zusätzlich einer Volksabstimmung.“

Man versteht, daß und warum ihm die Initiative i.S.d. Art. $61 \mathrm{VvB}$ weniger am Herzen lag. Daß er nicht auch Art. 54 Abs. 3 VvB aufnahm, war und ist unschädlich, solange die Auflösungskompetenz unabhängig von Art. 54 Abs. 3 VvB in Art. 62, $63 \mathrm{VvB}$ geregelt ist. Art. 72 Abs. $2 \mathrm{VvB}$ sollte zusätzlich aufgenommen werden. ${ }^{61}$ Satz 2 selbst ist freilich gegen eine Änderung gemäß Satz 1 des Art. 100 VvB formal nicht geschützt. ${ }^{62}$

Ein Satz 3, der den Gesetzgeber ermächtigt, Näheres zum Volksabstimmungsverfahren zu regeln, fehlt noch immer. Berlin behilft sich mit Adhoc-Regelungen, die an die einschlägige Verfassungsänderung angehängt werden und ihr folgen. ${ }^{63}$ Der angemessene Standort ist das Abstimmungsgesetz.

Unabhängig davon sollte überdacht werden, ob nicht die Verfassung insgesamt ein so gewichtiges Instrument ist, daß - wie in Bayern (Art. 75 Abs. 2 Satz 2) und Hessen (Art. 123 Abs. 2) - jede ihrer Änderungen durch das Parlament einem Referendum unterworfen werden sollte, gleichgültig, welches Thema oder welchen Umfang sie hat. Ein solches partnerschaftliches Vorgehen scheint mir auch deshalb besonders wichtig, weil die Berliner Verfassung - anders als viele unserer Verfassungen - keinen änderungsfesten Kern benennt, dem Abgeordnetenhaus insofern thematisch völlig freie Hand beläßt. Das Referendum gäbe dem Parlament zudem die Chance, die Verantwortung für die Änderung mit dem Volke zu teilen und sich zugleich zwischen den Wahlen der Übereinstimmung mit dem Volkswillen zu vergewissern. $\mathrm{Zu}$ fürchten hätte es nichts; am Referendum ist kaum je eine Verfassungsänderung gescheitert. ${ }^{64}$ Die Bürger werden die größere Verantwortung gern

Abs. 2 VvB 1950 bestimmte, daß das Abgeordnetenhaus aus 200 Abgeordneten bestehe, doch konnten nach der Spaltung der Stadt erstmals bei der Wahl am 3. Dezember 1950 davon nur die 127 Abgeordneten in den Westsektoren gewählt werden, nicht auch die 73 auf den Ostsektor entfallenden Kandidaten. Eine Anpassung des Art. 25 Abs. 2 an die neue Lage hätte die Spaltung insoweit verfassungsrechtlich festgeschrieben. Als Grundlage für die Berechnung der Quoren taugte die Bestimmung andererseits nicht mehr. Da konnte das Adjektiv ,gewählte“ für den Eingeweihten klarstellen, daß von 127 auszugehen war. - Sechs „Nichtgewählte“ gehörten dem Abgeordnetenhaus in der ersten Wahlperiode im übrigen beratend an (vgl. Sitzung des Abgeordnetenhauses vom 19. April 1951, AH-PIPr. 1/11, S. 221). Sie machten von dem Gesetz vom 27. März 1951 (GVB1. S. 297) Gebrauch, nach dem mit beratender Stimme die (17) ehemaligen Stadtverordneten dem Abgeordnetenhaus angehören sollten, die 1946 auf Kreiswahlvorschläge derjenigen Wahlkreise gewählt worden waren, ,in denen am 3. Dezember 1950 die Durchführung der Wahl durch höhere Gewalt verhindert war, und am 3. Dezember 1950 ihren Wohnsitz im Ostsektor hatten“.

60 Treffender wäre vielleicht „oder“.

61 Vgl. oben sub III 2 b).

62 Aber will man der Verfassung einen Satz wie „Eine Änderung des Artikels 62, des Artikels 63 und dieses Satzes 2 des Artikels 100 bedarf zusätzlich einer Volksabstimmung" zumuten?

63 Vgl. Art. II Abs. 2 des Achten Änderungsgesetzes sowie das Gesetz über die Durchführung der Volksabstimmung nach Artikel 100 Satz 2 der Verfassung von Berlin am 17. September 2006" (GVBl. S. 448; Kursivdruck nicht im Original).

64 Hessen 1995 ist womöglich das einzige Beispiel. 
übernehmen. Aus ihrer Sicht dürften Änderungen zum Beispiel ihrer Grundrechte und der Verfassungsbeschwerdemöglichkeit mindestens von gleichem Interesse und Gewicht sein wie ihre Abstimmungskompetenzen. Und sie werden Änderungen, die das Abgeordnetenhaus beschließt, nicht deswegen ablehnen, weil sie ihnen nicht auf ersten Blick und unmittelbar zugute kommen. ${ }^{65}$

\section{b) 2006: Verfassungsinitiative}

Alle Landesverfassungen sehen auf Verfassungsänderungen gerichtete Volksinitiativen (Volksbegehren) vor, alle bis auf die saarländische Verfassung (Art. 100 Abs. 4) auch Volksentscheide über Verfassungsänderungen. Warum auch sollten sie, wenn sie überhaupt Volksabstimmungskompetenzen kennen, ausgerechnet das wichtigste Gesetz dem Volk entziehen? Berlin hat sich bis 2006 davon nicht beeindrucken lassen. Bis 1995 mochte das noch in gewisser Weise konsequent erscheinen: Auch die einfache Gesetzgebung war ja bis dahin dem Volk verschlossen, und an den Verfassungsänderungen des Parlaments war das Volk auch nicht beteiligt. Aber dann, als man 1995 die alte Grundentscheidung für direkte Demokratie wieder erneuerte, wirkte es geradezu anachronistisch, die Verfassungsinitiative auszusparen, ${ }^{66}$ zumal Art. 88 Abs. 2 VvB 1950 noch $^{67}$ bestimmt hatte:

„Änderungen der Verfassung können auch im Wege des Volksentscheides erfolgen; die Zustimmung der Mehrheit der Stimmberechtigten ist erforderlich.“

Wie auch immer, die Verfassungsänderung von 2006 holte das Versäumte nach. Der Verfassungsvorbehalt (Art. 62 Abs. 5 VvB 1995: „Volksbegehren zur Verfassung, ... sind unzulässig.") wurde gestrichen. Damit galten die Vorschriften, die in Art. 62 VvB von „Gesetzen“ sprachen (Art. 62 Abs. 1 Sätze 1 und 3, Abs. 3-5 VvB i.d.F. der Änderung von 2006) nun auch für Verfassungsänderungsbegehren. Die 2006 aus Art. 62 Abs. 5 VvB 1995 als Absatz 2 des Art. 62 VvB übernommenen

65 Beispiel: die derzeit - Oktober 2009 - erwogene Änderung des Art. 55 Abs. 2 VvB („Der Senat besteht aus dem Regierenden Bürgermeister und bis zu acht Senatoren. “). Aus ,acht“ sollen ,zehn“ werden. Dafür sprechen gute Gründe. Noch bessere sprechen dafür, gar keine Zahl festzuschreiben. So halten es das Grundgesetz und zwölf Landesverfassungen. Nur Bayern (Art. 43 Abs. 2) sieht - wie bislang Berlin - eine Höchstzahl vor. Bremen (Art. 107 Abs. 1 Satz 2) und Hamburg (Art. 33 Abs. 3) ermächtigen den einfachen Gesetzgeber, die Zahl festzulegen; das beläßt der einfachen Parlamentsmehrheit eine nachhaltige Kontrolle und schwächt die Regierung.

66 Art. 62 Abs. 5 VvB 1995: „Volksbegehren zur Verfassung ... sind unzulässig.“

67 Bis zum unrühmlichen Kahlschlag 1974. Dessen eine - status-spezifische - Begründung (AHDrs. 6/1445, S. 2 li. Sp.) konnte allenfalls für die einfache Volksgesetzgebung, nicht aber für Verfassungsänderungen gelten. Die andere „Begründung“ - Zweifel an der Zweckmäßigkeit der Volksgesetzgebung in einem Repräsentativsystem (ebenda, S. 2 re. Sp.) - ließ sich allerdings bequem auf Verfassungsänderungen ausdehnen (vgl. denn auch ebenda, S. 2 re. Sp., 3 re. Sp. [mit zusätzlich kurioser Formulierung]). 
Bereichsausnahmen (,Volksbegehren zum Landeshaushaltsgesetz, ${ }^{68} \mathrm{zu}$ Dienst- und Versorgungsbezügen, Abgaben, Tarifen der öffentlichen Unternehmen sowie zu Personalentscheidungen") gelten naturgemäß für Verfassungsänderungsbegehren nicht. Sie können darauf gerichtet werden, Art. 62 Abs. 2 VvB zu ändern oder aufzuheben, oder darauf, ihn durch Änderung anderer Stellen der Verfassung beiseitezuschieben, ohne seinen Wortlaut anzutasten.

Hinzu kamen 2006 die nur für Verfassungsänderungsbegehren und -entscheide geltenden Quoren und Fristen des Art. 63 Abs. 3 VvB. Die Quoren lassen Mißbrauchssorgen nicht aufkommen. Daß sie höher liegen als bei einfachen Gesetzen, kann man akzeptieren; um wie vieles höher, wird immer im Streit sein. Wenn die Verfassung Wert darauf legt, die Bevölkerung für die direkte Demokratie auf Dauer zu mobilisieren, sollte sie auf Beteiligungsquoren (Art. 63 Abs. 3 Satz 3 VvB) allerdings verzichten.

681995 bis 2006: „Landeshaushalt“. 